\title{
Development and validation of the cancer self-perceived discrimination scale for Chinese cancer patients
}

\author{
Lin-sen Feng ${ }^{1}$, Xin-yue Li ${ }^{2}$, Hong-rong Wang ${ }^{3}$, Jing-jing Zhan² ${ }^{2}$ Dong Chen ${ }^{2}$ and Yu-feng Wang ${ }^{2 *}$
}

\begin{abstract}
Background: To develop a Cancer Self-Perceived Discrimination Scale (CSPDS) for Chinese cancer patients and to assess its reliability and validity.

Method: A total of 178 patients were recruited and the classical test theory was used to develop the CSPDS. Item analysis was adapted to improve the preliminary version of the CSPDS, then the reliability, the validity and the acceptability of the final version of CSPDS were assessed.

Results: This CSPDS contained 14 items classified into 3 subscales: social withdrawal with 7 items, stigma with 4 and self-deprecation with 3. Good validity $\left(X^{2} / \mathrm{df}=1.216, \mathrm{GFI}=0.935, \mathrm{AGFI}=0.903, \mathrm{I}-\mathrm{CVI}>\mathrm{s}>0.80\right)$ and good reliability (Cronbach's alpha $=0.829$, Spearman-Brown coefficient $=0.827$, test-retest reliability coefficient $=0.944$ ) were found. The completion time was $6.06 \pm 1.80 \mathrm{~min}$. Participants who were female and reported poor self-rated health tended to have higher CSPDS scores $(P<0.05)$.

Conclusions: The results indicated that this CSPDS could be used to assess the level of self-perceived discrimination and to preliminarily screen perceived discrimination among Chinese cancer patients, especially in Southwest China. It may provide a basis for scientific assessment of targeted patient education, psychological counseling, social interventions, and psychotherapy in the future.
\end{abstract}

Keywords: Cancer self-perceived discrimination scale, Psychological problems, Self-perceived discrimination

\section{Background}

Self-perceived discrimination, which is also called "perceived discrimination", is a type of negative psychological status. Once a group member begins to experience a process in which one is treated differently (especially unequally or disparagingly) [1], self-perceived discrimination, originating from the person's subjective feelings, is likely to arise (either intermittently or continually). It can reflect the level of actual discrimination or systematic over- or under-estimation of actual discrimination [2].

Discrimination exists in a variety of forms, for example, gender, race, income, social class, workplace, insurance, disease, etc. [3]. Disease-related discrimination refers to how healthy people intentionally exclude

\footnotetext{
* Correspondence: 13577037585@163.com

${ }^{2}$ The Third Affiliated Hospital of Kunming Medical University (Yunnan Cancer Hospital), Kunming 650118, Yunnan, China

Full list of author information is available at the end of the article
}

individuals with certain diseases or disabilities, thereby leading to isolation, prejudice, and discrimination towards them. Most literatures on disease-related discrimination have focused on pathogen carriers and patients with specific chronic infectious diseases (e.g., tuberculosis, AIDS, leprosy) [4-7], or on patients with mental disorders such as depressive disorder or schizophrenia $[8,9]$. Disease-related discrimination can come from both general population and medical professionals, so it is widespread and worthy of attention [10].

Cancer has become a common chronic disease worldwide $[11,12]$. The prevalence of long-term psychological effects of cancer cannot be neglected [13, 14], which attaches more importance to cancer-related self-perceived discrimination [15]. Patients can perceive discrimination due to fear of death and side effects from cancer treatments [16-19].

(c) The Author(s). 2018 Open Access This article is distributed under the terms of the Creative Commons Attribution 4.0 International License (http://creativecommons.org/licenses/by/4.0/), which permits unrestricted use, distribution, and reproduction in any medium, provided you give appropriate credit to the original author(s) and the source, provide a link to the Creative Commons license, and indicate if changes were made. The Creative Commons Public Domain Dedication waiver (http://creativecommons.org/publicdomain/zero/1.0/) applies to the data made available in this article, unless otherwise stated. 
Previous literature showed that cancer discrimination might originate from workplace and insurance. Workplace discrimination mainly included hiring discrimination, refusal of workplace accommodations, limited career advancement opportunities, and so on [20]. Genetic discrimination was another issue cancer patients are facing [21]. Researches had revealed that there were relations between cancers and gene mutations. For instance, hereditary breast and ovarian cancer (HBOC) was associated with mutations in BRCA [22]. In these patients, fears of health insurance discrimination and life insurance discrimination were well documented, which was the proof of the existance of genetic discrimination in insurance [21].

However, there is no proper measure to assess cancer self-perceived discrimination since there has been only a very few scales specifically evaluating stigma and shame. Cataldo JK designed the Cataldo Lung Cancer Stigma Scale (CLCSS) with 31 items and four subscales (stigma and shame, social isolation, discrimination and smoking) based on the HIV Stigma Scale, and he paid more attention to the relationship between smoking status and lung cancer stigma [23]. Kissane DW developed a 20-item Shame and Stigma Scale (SSS) for head and neck cancer which contained 4 subscales: shame with appearance, sense of stigma, regret, and speech/social concerns, and he focused on shame and stigma after alteration of body image and functions [24]. These scales had excellent reliability and validity, but they only focused on stigma which was just a part of cancer-related discrimination and were limited to a single type of cancer.

The purpose of our study was to develop a comprehensive Cancer Self-Perceived Discrimination Scale (CSPDS) to assess the level of self-perceived discrimination among Chinese cancer patients.

\section{Methods}

\section{Study design and participants}

The classical test theory was adapted, and the steps were as follows:

(1) Develop a preliminary CSPDS based on semistructured interviews, literature reviews, expert consultations and cognitive interviewing.

(2) Collect data of the hospitalized cancer patients interviewed using the preliminary CSPDS.

(3) Generate final version of CSPDS using item analysis.

(4) Validate the final CSPDS.

(5) Subgroup-analysis of the final CSPDS.

The inclusion criteria were as follows: patients were/had

- $\geq 18$ years old;

- with cancers confirmed by pathology;
- aware of their own diagnosis for at least one month;

- volunteered for participation;

- the ability to complete the survey on their own or with the help of investigators;

- basic communication skills and understanding capability.

The exclusion criteria were as follows: if patients

- had a past or present chronic infectious disease or mental disorder;

- had severe vision or hearing loss, cognitive dysfunction, or disturbance of consciousness;

- had been critically ill and undergone emergency medical treatment.

Another additional inclusion criterion, having experienced discrimination after diagnosis for more than one month, was included during the semi-structured and the cognitive interviews.

This was a single-center study. All participants were from the Third Affiliated Hospital of Kunming Medical University (Yunnan Cancer Hospital), Kunming, Yunnan Province, Southwest China.

\section{Quesitonaire development and item selection \\ Step 1}

The "information-saturated method" was adopted to determine the sample size, therefore, the patient samples depended on whether there was any further information in the semi-structured interviews [25]. The semi-structured interviews were concluded once no more information emerged. Eleven cancer patients participated in the semi-structured interviews (August 1 - September 10, 2014), among which 5 were from urban areas and 6 from rural areas; 4 out of these 11 accepted higher education, 5 secondary education and 2 primary education; 4 out of these 11 came from families with economic poverty and the rest are well-off. To ensure interviewees' privacy and improve the authenticity of the data, the interviews were conducted face-to-face by professionals in a one-on-one capacity. Each interview was finished within $45 \mathrm{~min}$. As most interviewees refused sound recording, all interviews were recorded by transcripts. The interviews focused on self-perceived discrimination after cancer diagnosis.

Standard definitions of discrimination and cancer-related discrimination were provided to the interviewees. The definition of discrimination is treating a person or a particular group of people differently, especially in a worse way compared with the way in which one treats other people, because of their skin colour, sex, sexuality, etc. By that analogy, the definition of cancer-related discrimination is treating the cancer patients differently, especially in a worse way compared with the way in which one treats 
other people, because of their cancer, disease manifestations, treatment-related toxicity, etc. Sample questions included "Have you ever experienced discrimination because of your disease?" "What kind of discrimination did you experience?" and "What was the impact of that discrimination?". The interviewer had to make sure that interviewees did not wander off topic and interview contents were fully recorded. If at least three interviewees complained of the similar issues related to discrimination, we extracted them into the item pool. The interviews were analyzed and transcribed into text by two language experts in concise and understandable language as the final items.

\section{Step 2}

Literature on disease-related discrimination, particularly cancer, infectious disease, and mental disorders, was reviewed (August 5-September 3, 2014) [23, 24, 26, 27]. Language design of the item pool was borrowed from the literature reviewed, including grammar and the sentence patterns. Then the item pool was developed through the semi-structured interviews and literature reviews.

A five-point Likert scale was used for item responses. For the forward-scored items, the options were as follows: $1=$ strongly disagree, $2=$ somewhat disagree, $3=$ neither agree nor disagree, $4=$ somewhat agree, and $5=$ strongly agree; for the reversed-scored items, the scoring was reverse. Thus, higher scores indicated stronger levels of self-perceived discrimination.

\section{Step 3}

Four oncologists and three experienced nurses were invited to assess the suitability of the items twice (September 19September 30, 2014). After the first consultation, those inaccurate words or items were further adjusted and revised. The second consultation was to calculate the item-level content validity indexes (I-CVIs) [28]. The suitability of each item was reviewed and judged by the experts independently, with a 3 -point rating scale $(3=$ completely relevant to $1=$ completely irrelevant). If the index was $<0.8$, we would repeat the former steps until it was $\geq 0.8$.

\section{Step 4}

The cognitive interviewing was conducted to ensure whether all of the items were applicable for formal investigations. Twenty interviewees were invited for verbal probing, which was a method of cognitive interviewing with patients (October 10-October 25, 2014). In the first round, 10 interviewees finished every item in the scale and answered the question "can you repeat the items you just read in your own words?". Then we revised relevant words based on the first round. Next, 10 other interviewees participated in the second round of verbal probing to ensure that each item IS concise, clear, accurate and unambiguous. If any ambiguous words existed, we would revise and invite another 10 patients to run the cognitive interviewing again.

\section{Data collection}

The questionnaire is composed of three parts: an assessment of sociological characteristics (gender, age, marital status, residence, number of family members, average monthly family income, educational background, occupational classification, medical insurance, and self-rated health status), the preliminary CSPDS, and the basic clinical information (diagnosis and treatments). A common recommendation for the minimum necessary sample size for a factor analysis is $N=100$, with a subject-to-variable ratio of no less than $5[29,30]$.

To create a quiet atmosphere and avoid interference, the questionnaire was administered during non-visiting hours. There were six investigators including oncologists, medical postgraduate students, and clinical medicine undergraduates, who were all qualified in unified training. Before issuing questionnaires, the inclusion criteria and exclusion criteria of formal investigations were used to identify the potentially eligible patients through hospital records. All participants were inpatients. In principle, the questionnaire was completed by participants themselves. When requested, investigators read the items to the patients but the patients provided the answers (usually performed when the patient had limited mobility). The formal investigation was done between November 2014 and February 2016.

\section{Analysis \\ Step 1: Item analysis}

Pearson correlation coefficient was used to examine correlations between each item's score and the total score, and items would be removed if the correlation coefficient was small $(\gamma<0.3)$ or was insignificant $(P>0.05)$, or if it lowered the Cronbach's alpha of the scale.

\section{Step 2: Validity}

The construct validity of the final CSPDS was verified using confirmatory factor analysis (CFA) and structural equation modeling (SEM). According to the developing design of the CSPDS, we proposed two models for validation: an uncorrelated three-factor model and a correlated three-factor model. The good model-fitting degree included probability level $(P>0.05)$, Chi-Square divided by degrees of freedom $\left(\mathrm{x}^{2} / \mathrm{df}<2\right)$, goodness of fit index (GFI $>0.90$ ), adjusted goodness of fit index (AGFI $>0.90$ ), comparative fit index (CFI $>0.95$ ), normed fit Index (NFI $>0.90$ ), Tucker-Lewis index (TLI >0.95), and root mean squared error of approximation (RMSEA < 0.05) [31, 32]. The content validity was confirmed using I-CVIs and Pearson correlation analysis. 


\section{Step 3: Reliability}

Cronbach's alpha and Spearman-Brown coefficient with a minimum of 0.70 suggest a good internal reliability [33, 34]. Test-retest reliability was verified using intra-class correlation coefficients (ICCs), with an interval of one week between the first and the second test. An ICC greater than 0.80 indicates that the two tests had excellent test-retest reliability [35].

\section{Step 4: Acceptability}

The readability score was valued using Flesch Reading Ease and Flesch-Kincaid Grade Level (Office Word 2013, Microsoft Corp., USA), and the survey completion time was recorded.

\section{Step 5: Subgroup-analysis}

The CSPDS subgroup analysis based on gender, age, marital status, residence, family numbers, family income, education, occupation, self-rated health, time since diagnosis, medical insurance and cancer type was performed, using a one-way analysis of variance and Fisher's least significant difference test (LSD-t) as well.

The statistical analysis was performed using Stata 12.0 (Stata Corp., USA) and Amos 19.0 (IBM, USA). The two tailed $P \leq .05$ was considered significant.

\section{Results}

\section{Sample characteristics}

Two hundred ten cancer patients were approached, and 190 patients consented to participate, among which 178 patients completed the survey (the valid response rate was 93.68\%). Among the 178 participants, 53 patients had lung cancer, 45 had gynecologic malignancies (including 24 ovarian cancer, 9 endometrial cancer, and 12 cervical cancer), 22 had breast cancer, 21 had head and neck cancer, 21 had gastrointestinal cancer, and 16 had lymphomas. The mean age was 53 years old (range: $19-80$ years old). The mean time from the diagnosis to the interviews was 11.5 months (range: 1-204 months). Detailed information about the sample characteristics is shown in Table 1.

\section{Development of the preliminary version of CSPDS}

According to the semi-structured interviews, self-perceived discrimination could be conceptualized as three subscales: social withdrawal, stigma and self-deprecation. There were 21 items in the original scale. Among them, 9 items were about social withdrawal factor, 8 items about stigma factor, and 4 items about self-deprecation factor; 16 were forward-scored and 5 items were reversed-scored. We revised the wording of 8 items after the first expert consultation. All I-CVIs of the 21 items were $>0.80$ after the second consultation. No word amendment was required as the 2 times verbal probing finished (Table 2).
Table 1 Scores of participant characteristics (Mean \pm SD)

\begin{tabular}{|c|c|c|c|}
\hline Characteristics & $N$ & Total scores & $P$ \\
\hline \multicolumn{4}{|l|}{ Gender } \\
\hline Male & 75 & $35.28 \pm 11.07$ & \multirow[t]{2}{*}{0.007} \\
\hline Female & 103 & $39.99 \pm 11.51$ & \\
\hline \multicolumn{4}{|l|}{ Age } \\
\hline $18-45$ & 39 & $38.62 \pm 9.90$ & \multirow[t]{3}{*}{0.128} \\
\hline $46-59$ & 88 & $39.32 \pm 11.30$ & \\
\hline$\geq 60$ & 51 & $35.27 \pm 12.77$ & \\
\hline \multicolumn{4}{|l|}{ Marital status } \\
\hline Married & 159 & $37.61 \pm 11.08$ & \multirow[t]{2}{*}{0.186} \\
\hline Unmarried & 19 & $41.32 \pm 14.72$ & \\
\hline \multicolumn{4}{|l|}{ Residence } \\
\hline Urban area & 116 & $38.10 \pm 11.44$ & \multirow[t]{2}{*}{0.877} \\
\hline Rural area & 62 & $37.82 \pm 11.79$ & \\
\hline \multicolumn{4}{|l|}{ Family numbers } \\
\hline$\leq 3$ & 91 & $37.46 \pm 11.14$ & \multirow[t]{2}{*}{0.521} \\
\hline$\geq 4$ & 87 & $38.57 \pm 11.96$ & \\
\hline \multicolumn{4}{|l|}{ Average monthly family income } \\
\hline$\leq ¥ 3000$ & 78 & $39.04 \pm 12.77$ & \multirow[t]{3}{*}{0.352} \\
\hline$¥ 3001-6000$ & 60 & $38.13 \pm 10.30$ & \\
\hline$\geq ¥ 6001$ & 40 & $35.80 \pm 10.66$ & \\
\hline \multicolumn{4}{|l|}{ Education } \\
\hline Junior middle school and below & 91 & $37.25 \pm 13.08$ & \multirow[t]{2}{*}{0.371} \\
\hline Senior high school and above & 87 & $38.79 \pm 9.66$ & \\
\hline \multicolumn{4}{|l|}{ Occupational classification } \\
\hline Retiree & 59 & $38.07 \pm 11.98$ & \multirow[t]{4}{*}{0.066} \\
\hline Civil servant or institution officer & 38 & $40.34 \pm 6.89$ & \\
\hline Farmer or migrant worker & 53 & $38.91 \pm 12.91$ & \\
\hline Freelance professional & 28 & $33.00 \pm 11.91$ & \\
\hline \multicolumn{4}{|l|}{ Self-rated health } \\
\hline Good & 41 & $33.15 \pm 11.44$ & \multirow[t]{3}{*}{0.001} \\
\hline Average & 89 & $38.08 \pm 10.98^{\mathrm{a}}$ & \\
\hline Poor & 48 & $42.02 \pm 11.24^{\mathrm{ab}}$ & \\
\hline \multicolumn{4}{|l|}{ Time since diagnosis } \\
\hline$\leq 12$ months & 96 & $36.78 \pm 11.52$ & \multirow[t]{2}{*}{0.126} \\
\hline$>12$ months & 82 & $39.44 \pm 11.45$ & \\
\hline \multicolumn{4}{|l|}{ Medical insurance } \\
\hline Urban basic health insurance & 121 & $37.83 \pm 11.22$ & \multirow[t]{2}{*}{0.556} \\
\hline New rural cooperatives medical service & 55 & $38.93 \pm 12.04$ & \\
\hline \multicolumn{4}{|l|}{ Cancer Type } \\
\hline Lung cancer & 53 & $35.98 \pm 10.08$ & \multirow[t]{6}{*}{0.130} \\
\hline Gynecologic malignancies & 45 & $40.84 \pm 11.95$ & \\
\hline Breast cancer & 22 & $41.73 \pm 11.41$ & \\
\hline Head and neck cancer & 21 & $37.62 \pm 12.56$ & \\
\hline Gastrointestinal cancer & 21 & $35.43 \pm 10.36$ & \\
\hline Lymphomas & 16 & $35.50 \pm 13.67$ & \\
\hline
\end{tabular}




\section{Item analysis}

(1) Correlational analysis-The correlation coefficients of item 6 , item 13 , item 14 , item 17 , item 19, item 20 and item 21 were 0.201, 0.267, $0.238,0.256,0.194,0.289$, and 0.127 , respectively. The correlation coefficients of the remaining 14 items ranged from 0.388 to $0.640(P<.001)$.

(2) Cronbach's alpha-The Cronbach's alpha of the preliminary scale was 0.781 , and it was significantly increased with the removal of item $6,13,14,17,19$, 20 and 21 (See 3.5). The remaining items were renumbered to form the final 14-items CSPDS (Table 2).

\section{Construct validity and content validity}

The goodness of fitting of the three-factor model coincided with the initial conception of the scale's general structure excellently (Fig. 1, Table 3). The fitting degree of the correlated three-factor model was better than the uncorrelated three-factor model. Factor 1 meant "social withdrawal"; it mainly described how cancer patients began to withdraw contact with people after being diagnosed. Factor 2 was labeled "stigma"; it reflected the fact that patients felt their reputation had been unfairly maligned as a result of their disease. Factor 3 was labeled "self-deprecation"; it reflected patients' negative attitudes toward themselves under multiple burdens derived from their health, mentality, society, finances, or fear of death.

Since I-CVIs of every item in the preliminary CSPDS (21 items version) was $\geq 0.80$, the I-CVIs in the final 14 items version were all $\geq 0.80$ definitely. The correlation coefficients of each item were strongly related to the total scale by Pearson correlation analysis ( $\gamma$ ranging from 0.381 to $0.655, P<0.01)$. The coefficients between each item and the subscale ranged from 0.471 to $0.839(P<0.01)$. Therefore, the CSPDS had a good content validity.

\section{Reliability}

The Cronbach's alpha for the final CSPDS was 0.829, while those for the three subscales were $0.781,0.759$ and 0.754 , respectively. In addition to alphas, the Spearman-Brown coefficients of the total scale and the three subscales were $0.827,0.803,0.781$ and 0.782 , respectively, indicating

Table 2 Item analysis and final version of CSPDS

\begin{tabular}{|c|c|c|c|}
\hline Draft version of CSPDS & Factor & Item analysis & $\begin{array}{l}\text { Final version of CSPDS } \\
\text { (Renumber) }\end{array}$ \\
\hline 1. I will be very happy if someone would like to visit me in the hospital. & F1 & $\sqrt{ }$ & Item 1 \\
\hline 2. Cancer means fewer and fewer friends & $\mathrm{F} 1$ & $\sqrt{ }$ & Item 2 \\
\hline 3. Sometimes, I am ashamed when I face other people. & $\mathrm{F} 1$ & $\sqrt{ }$ & Item 3 \\
\hline 4. People look down upon cancer patients. & $\mathrm{F} 1$ & $\sqrt{ }$ & Item 4 \\
\hline 5. I hate others talking about my disease behind me. & F1 & $\sqrt{ }$ & Item 5 \\
\hline 6. I'd like to talk about my disease with others. & F1 & $\times$ & \\
\hline 7. I hate someone staring at me. & $\mathrm{F} 1$ & $\sqrt{ }$ & Item 6 \\
\hline 8. Having cancer is because of sin. & $\mathrm{F} 2$ & $\sqrt{ }$ & Item 7 \\
\hline 9. It would be bad for me if too many people know the state of my disease. & F1 & $\sqrt{ }$ & Item 8 \\
\hline $\begin{array}{l}\text { 10. People would not like to approach patients because they believe cancer } \\
\text { is a contagious disease. }\end{array}$ & $\mathrm{F} 2$ & $\sqrt{ }$ & Item 9 \\
\hline $\begin{array}{l}\text { 11. People would deliberately avoid meeting cancer patients because they } \\
\text { think cancer patients will borrow money from them. }\end{array}$ & $\mathrm{F} 2$ & $\sqrt{ }$ & Item 10 \\
\hline 12. People believe that it will bring bad luck to contact cancer patients. & $\mathrm{F} 2$ & $\sqrt{ }$ & Item 11 \\
\hline 13. I would not like to go to public place. & $\mathrm{F} 1$ & $\times$ & \\
\hline 14. Many people believe that cancer treatments are effective. & F3 & $\times$ & \\
\hline 15. Sometimes, I feel I am unlucky. & F3 & $\sqrt{ }$ & Item 12 \\
\hline 16. Sometimes, I feel I am useless. & F3 & $\sqrt{ }$ & Item 13 \\
\hline 17. All family member have provided sufficient care for me since I was ill. & F2 & $\times$ & \\
\hline 18. I am a burden of my family. & F3 & $\sqrt{ }$ & Item 14 \\
\hline 19. Some people give counterfeit drugs to cheat cancer patients. & F2 & $\times$ & \\
\hline 20. Cancer patients are vulnerable to be treated unfairly by insurance. & $\mathrm{F} 2$ & $\times$ & \\
\hline $\begin{array}{l}\text { 21. Community or village committee have provided sufficient care for me } \\
\text { since my disease. }\end{array}$ & $\mathrm{F} 2$ & $\times$ & \\
\hline
\end{tabular}




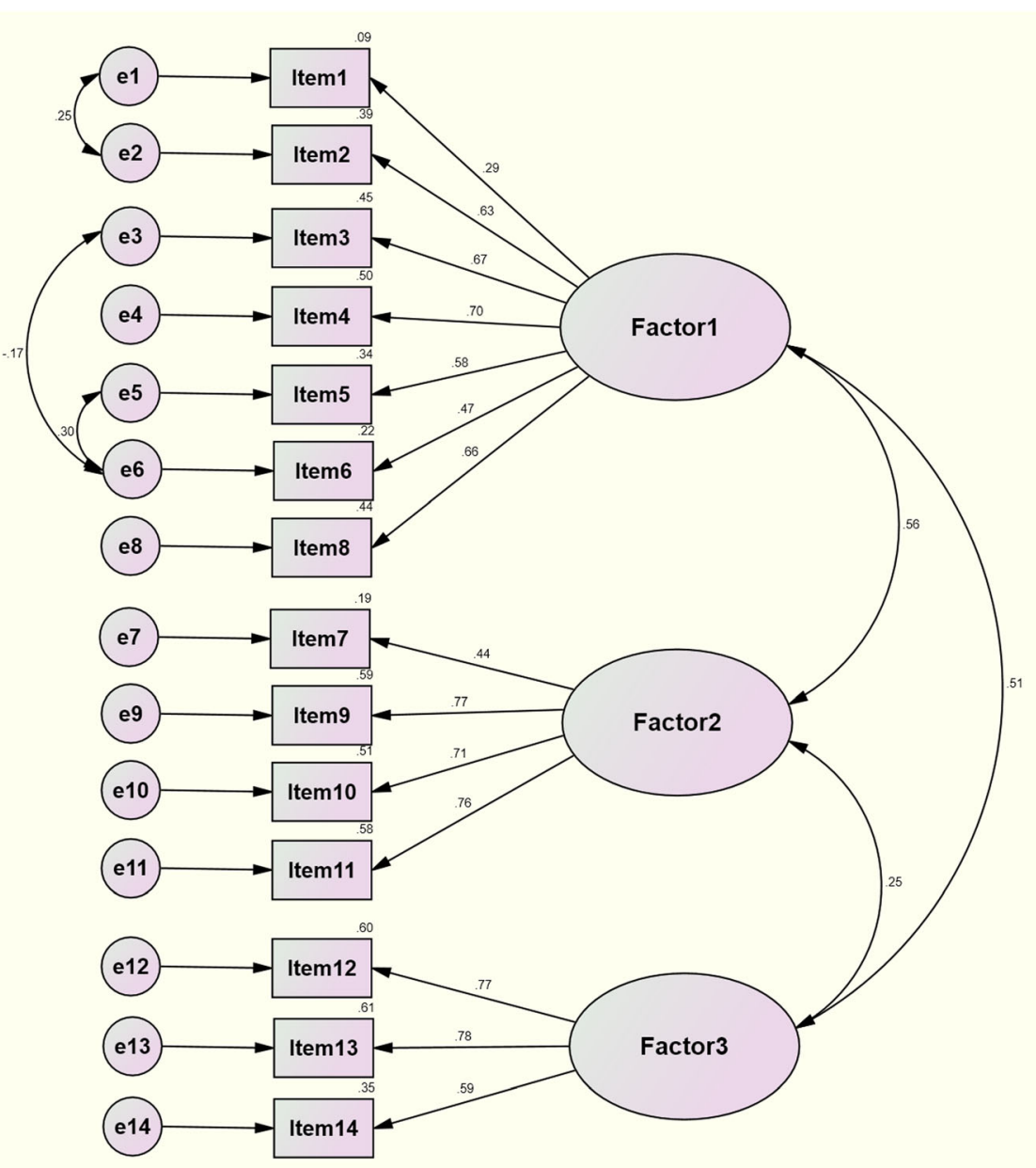

Fig. 1 The structural equation modeling of CSPDS

sufficient internal reliability of the CSPDS. One week after the first interview, a total of 22 patients took part in the second test for test-retest reliability. The test-retest reliability coefficients for the CSPDS and subscales were all excellent, and the ICC of the CSPDS and the 3 subscales were 0.944, 0.926, 0.893, and 0.854 , respectively (Table 4 ).

\section{Acceptability}

The completion time of the final 14-item CSPDS was $6.06 \pm 1.80$ (range: 3 to 9) minutes. The Flesch Reading
Ease of final CSPDS in English was 60.1, and the Flesch-Kincaid Grade Level was 7.5.

\section{Subgroup-analysis}

Regarding the CSPDS total scores, significant differences were found in genders and self-rated health status $(P<0.05)$. The total score of the participants reporting poor self-rated health $(42.02 \pm 11.24)$ was higher than that of the participants reporting good health $(33.15 \pm 11.44 ; P<0.001)$ and average health $(38.08 \pm 10.98 ; P=0.05)$. The total score of the participants reporting average health was higher than that

Table 3 Fit indices of confirmatory factor analysis for CSPDS

\begin{tabular}{lllllllll}
\hline Factor structure & $P$ & $X^{2} / \mathrm{df}$ & GFI & AGFI & CFI & NFI & TLI & RMSEA \\
\hline Uncorrelated three-factor model & 0.001 & 1.562 & 0.916 & 0.880 & 0.939 & 0.851 & 0.925 & 0.056 \\
Correlated three-factor model & 0.104 & 1.216 & 0.935 & 0.903 & 0.978 & 0.889 & 0.971 & 0.035 \\
Threshold & $>0.05$ & $<2$ & $>0.90$ & $>0.90$ & $>0.95$ & $>0.90$ & $>0.95$ & $<0.05$ \\
\hline
\end{tabular}


Table 4 Reliability of the CSPDS and three subscales

\begin{tabular}{llllr}
\hline & Cronbach's & Split-half reliability (Spearman-Brown coefficient) & \multicolumn{2}{c}{ Test-retest reliability } \\
\hline CSPDS & & 0.827 & ICC & 0.944 \\
Social withdrawal & 0.829 & 0.803 & 0.926 & $0.870-0.976$ \\
Stigma & 0.781 & 0.781 & $0.8931-0.969$ \\
Self-deprecation & 0.759 & 0.782 & 0.854 & $0.761-0.954$ \\
\hline
\end{tabular}

of those reporting good health $(P=0.02)$. In contrast, no significant differences were detected in any other characteristics $(P>0.05$; Table 1$)$.

\section{Discussion}

Our research showed that cancer-related self-perceived discrimination has three main subscales: social withdrawal, stigma, and self-deprecation, therefore the 14-item CSPDS was developed using the classical test theory. There was a high fit degree between the three factor structure and the initial conception $\left(\chi^{2} / \mathrm{df}=1.216\right.$, GFI $=0.935$, AGFI $=0.903$ ), the I-CVIs and Pearson correlations of content validity were all at a satisfactory level, which confirmed that the CSPDS had a good instrument validity. It also has a good stability measured by Cronbach's alpha (0.829), Spearman-Brown coefficient (0.827), and ICC (0.944). Its survey completion time and readability scores are at acceptable levels. Thus, it can be used to assess cancer-related discrimination in terms of social withdrawal, stigma, and self-deprecation.

The CSPDS is more comprehensive and more concise compared with CLCSS and SSS. Although the Cronbach's alpha of the CSPDS may be lower than the 31-item CLCSS (Cronbach's alpha $=0.96$ ) and the 21-item SSS (Cronbach's alpha $=0.94$ ) [23, 24], the CSPDS had excellent test-retest reliability and construct validity, and less items. While the social withdrawal/isolation and stigma subscales and items in the CSPDS are similar to the CLCSS and the SSS, we include the self-deprecation subscale. Most patients, when interviewed, expressed that self-deprecation was a major cause of self-perceived discrimination, therefore, its inclusion could be useful.

The CSPDS has a wider scope of application than the CLCSS and the SSS. The SSS focuses on the influence of the facial tissue defect in patients with head and neck cancer [24]. The CLCSS was used primarily in lung cancer patients with a history of smoking, because researchers considered stigma was based on the belief that smoking is the major cause of one's own cancer [36]. But lung cancer patients in China may not consider smoking a stigma or a cause of discrimination. The prevalence of smoking is very high in China, therefore, not like in U.S. or in Europe, there is no nationwide strict anti-smoking laws. Even through No-smoking signs are eye-catching in public places, smokers will not obey. These two scales are both limited to a single kind of cancer, or a single cause of cancer. However, the CSPDS can be applied to assess all kinds of cancer and could be a more promising tool of primary screening of self-perceived discrimination.

Notably, the CSPDS shows obvious differences in patients with different self-rated health states and genders. The CSPDS scores of participants who reported poor or average self-rated health state were higher than those who reported good state. It may indicate that perceived discrimination of cancer patients is positively correlated with subjective severity of the disease [36]. The result that women had higher scores than men could be linked to feminine psychological characteristics, social status, family status, and even sexual discrimination, however, we believe cancer is a catalyst for the discrimination against them. Women's family and social status in poor rural areas is far below the national average level in China [37]. Consequently, when women in poor Southwest China suffer from cancer, the discrimination against them would get worse or be newly genarated. Factors such as feudal thoughts or male chauvinism could lead to the beliefs that ill women are useless and a burden to the family, therefore they become victims of cancer-related discrimination.

Previous studies about cancer-related discrimination focused on workplace and insurance. However, in our semi-structured interviews with the 11 patients, no one described obvious workplace discriminatory behaviors in any form, so we did not include items of workplace discrimination in the preliminary version of the CSPDS. When comparing the participants' characteristics, results of occupational classification showed negative. This may be connected with Chinese health retirement policy, fair employment policy, and older age sample selection.

In this study, we find no obvious basic medical insurance discrimination. In our semi-structured interviews, 3 interviewees complained that they had experienced insurance discrimination following cancer, so we did set the item "Cancer patients are vulnerable to be treated unfairly by insurance" in the preliminary version, but it was deleted after the item analysis. Our study showed 176 participants used basic health insurance (2 didn't use medical service were excluded). Chinese basic health 
insurance schemes have achieved full coverage. It means that more than 1.17 billion people have access to basic health insurance schemes. Chinese basic health insurance system is divided into the Urban and Rural Resident Medical Insurance (URRMI) and the Urban Employee Medical Insurance (UEMI). Chinese government is trying to help ordinary people to pay for their medical costs. In general, Chinese people have an easy access to median low-level medical facilities, and an easy access general hospitals or specialized hospitals [38]. Patients with extreme real-life difficulties can enjoy extra medical subsidies from the government. The Chinese government has also established a Medical insurance for major diseases, to reimburse the high medical expenses of major diseases such as malignant tumors for urban and rural residents. These measures have been further easing the phenomenon that some patients are back to poverty because of those major diseases. Some charities and pharmaceutical companies have also launched charitable assistance programs against high-priced cancer drugs, further increasing access to high-priced cancer drugs for patients with financial difficulties.

In clinical treatment, some cancer patients suffer from social discrimination, which can have a negative impact on their health. The CSPDS would be helpful in discovering this problem in a timely manner. We envisage this measure being properly administered in terminal cancer patients and long-term cancer survivors. The stigma, rejection and isolation cancer patients suffering could come from the public's fear of death [16]. Terminal cancer patients are always in poor physical condition, and confronted with the threat of death. Our results suggest that the patients reporting poor self-rated health suffered more discrimination than those reporting good health or average health. So terminal cancer patients may experience more perceived discrimination. Besides, perceived discrimination is a negative psychological factor. Long-term cancer survivors could perceive more negative impacts of cancer. These perceptions appear to influence, or are potentially influenced by, physical and mental health-related quality of life [39]. Therefore we think that long-term cancer survivors also may experience more perceived discrimination.

Having taken those into consideration, the CSPDS may be more appropriate for preliminary screening of perceived discrimination. Furthermore, the CSPDS may help to develop targeted patient education, psychological diagnosis, psychological counseling or treatment, and social interventions, so as to improve patients' quality of life and social functioning as well as to prolong survival time among cancer patients.

As an exploratory study, this study has relatively few inpatients from a single center. The samples come mainly from South-western China, where is underdeveloped, so this result represents only patients in Southwest China.
Future studies should cover multiple areas and centers with larger samples, comparing the self-perceived discrimination levels in different types of cancer, and evaluating the correlations between self-perceived discrimination and other negative psychological states (e.g. anxiety, depression, disease uncertainty, post-traumatic stress disorder, etc), so as to provide more abundant evidence for cancer-related discrimination. Furthermore, as there is no authoritative or widely agreed standard measure in this field, we did not assess the criterion-related validity of the CSPDS. Moreover, if any researcher need to use this measure, we allow him/ her to translate it into other languages and further verify the reliability and validity, or revise it.

Further studies will be required to identify the precise relationship between gender and cancer-related discrimination. In view of possible workplace and insurance discrimination, young cancer patients and long-term survivors should be studied to determine whether workplace discrimination is in existence, and how it would influence the patient. More varieties of commercial insurance discrimination, such as health insurance, life insurance and endowment insurance, will also be considered in later stuies.

\section{Conclusion}

The CSPDS is accurate and reliable in our study, which could be used for assessing self-perceived discrimination among cancer patients and as a basis for patient education, counseling, social interventions, and psychotherapy in the future, at least in Southwest China.

\section{Abbreviations}

AGFl: Adjusted goodness of fit index; CFA: Confirmatory factor analysis; CFI: Comparative fit index; CLCSS: Cataldo Lung Cancer Stigma Scale; CSPDS: Cancer Self-Perceived Discrimination Scale; GFI: Goodness of fit index HBOC: Hereditary breast and ovarian cancer; ICCs: Intra-class correlation coefficients; I-CVIs: Item-level content validity indexes; LSD-t: Fisher's least significant difference test; NFI: Normed fit Index; RMSEA: Root mean squared error of approximation; SEM: Structural equation modeling; SSS: Shame and Stigma Scale; TLI: Tucker-Lewis index; $x^{2} / d f$ : Chi-Square divided by degrees of freedom

\section{Acknowledgments}

We would like to extend our heartfelt gratitude to all patients for their participation.

\section{Funding}

This study was supported by Yunnan Provincial Department of Education Research Fund (No. 2015z089) and Program of Philosophy and Social Science Fundation of Yunnan Province (No. QN2018018).

\section{Availability of data and materials}

The datasets used and/or analyzed during the current study are available from the corresponding author on reasonable request.

\section{Authors' contributions}

LF: Study design, data analysis and manuscript preparation. XL, HW, JZ and DC: Data collection. YW: Study design, data interpretation and manuscript modification. All authors read and approved the final manuscript.

Ethics approval and consent to participate

This study was approved by the Ethical Committee of the Third Affiliated Hospital of Kunming Medical University. Its procedure followed the 
Declaration of Helsinki. All participants provided a written informed consent form prior to the study.

\section{Consent for publication}

Not applicable.

\section{Competing interests}

The authors declare that they have no competing interests.

\section{Publisher's Note}

Springer Nature remains neutral with regard to jurisdictional claims in published maps and institutional affiliations.

\section{Author details}

${ }^{1}$ The Sixth Affiliated Hospital of Kunming Medical University (The People's Hospital of Yuxi), Yuxi 653100, Yunnan, China. ${ }^{2}$ The Third Affiliated Hospital of Kunming Medical University (Yunnan Cancer Hospital), Kunming 650118, Yunnan, China. ${ }^{3}$ The People's Hospital of Jiangchuan District, Yuxi 652600, Yunnan, China.

Received: 13 September 2017 Accepted: 25 July 2018

Published online: 14 August 2018

\section{References}

1. Krieger N. A glossary for social epidemiology. J Epidemiol Community Health. 2001:55:693-700

2. Hartung FM, Renner B. Perceived and actual social discrimination: the case of overweight and social inclusion. Front Psychol. 2013;4:147.

3. Gil-González D, Vives-Cases C, Borrell C, et al. Social determinants of selfperceived discrimination in Spain. Public Health. 2013;127:223-30.

4. Feng $D, X u L$. The relationship between perceived discrimination and psychological distress among Chinese pulmonary tuberculosis patients: the moderating role of self-esteem. Psychol Health Med. 2015;20:177-85.

5. Xiaoyou S, Lau JTF, Mak WWS, et al. Perceived discrimination, social support, and perceived stress among people living with HIV/AIDS in China. AIDS Care. 2013;25:239-48

6. Brakel WHV, Sihombing B, Djarir H, et al. Disability in people affected by leprosy: the role of impairment, activity, social participation, stigma and discrimination. Glob Health Action. 2012:5:18394.

7. Genberg BL, Kawichai S, Chingono A, et al. Assessing HIV/AIDS stigma and discrimination in developing countries. AIDS Behav. 2008;12:772-80.

8. Antonio L, Silvia Z, Tine VB, et al. Global pattern of experienced and anticipated discrimination reported by people with major depressive disorder: a cross-sectional survey. Lancet. 2013;381:55-62.

9. Bifftu BB, Dachew BA, Tiruneh BT. Stigma resistance among people with schizophrenia at Amanuel mental specialized hospital Addis Ababa, Ethiopia: a cross-sectional institution based study. BMC Psychiatry. 2014;14:259.

10. Harriet D, Andrew B. Commentary: factors affecting HIV/AIDS-related stigma and discrimination by medical professionals. Int J Epidemiol. 2007;36:185-6.

11. Ferlay J, Soerjomataram I, Dikshit R, et al. Cancer incidence and mortality worldwide: sources, methods and major patterns in GLOBOCAN 2012. Int J Cancer. 2015:136:E359-86.

12. Chen W, Zheng R, Zhang S, et al. Report of cancer incidence and mortality in China, 2010. Ann Transl Med. 2014;2:61.

13. Stein KD, Syrjala KL, Andrykowski MA. Physical and psychological long-term and late effects of cancer. Cancer. 2008;112:2577-92.

14. Vos MS, Putter $\mathrm{H}$, Houwelingen HCV, et al. Denial and social and emotional outcomes in lung cancer patients: the protective effect of denial. Lung Cancer. 2011:72:119-24.

15. Pascoe EA, Laura SR. Perceived discrimination and health: a meta-analytic review. Psychol Bull. 2009;135:531-54.

16. Mosher CE, Sharon DB. Death anxiety and cancer-related stigma: a terror management analysis. Death Stud. 2007;31:885-907.

17. Phelan SM, Griffin JM, Jackson GL, et al. Stigma, perceived blame, self-blame, and depressive symptoms in men with colorectal cancer. Psychooncology. 2013:22:65-73

18. Jennifer MS, Ubel PA, Atisha DM, et al. The choice for breast cancer surgery: can women accurately predict postoperative quality of life and diseaserelated stigma? Ann Surg Oncol. 2011;18:2477-82.

19. Rosman S. Cancer and stigma: experience of patients with chemotherapyinduced alopecia. Patient Educ Couns. 2004;52:333-9.
20. Stergiou-Kita M, Pritlove C, Kirsh B. The "Big C"—stigma, cancer, and workplace discrimination. J Cancer Surviv. 2016:10:1-16.

21. Allain DC, Friedman S, Senter L. Consumer awareness and attitudes about insurance discrimination post enactment of the genetic information nondiscrimination act. Familial Cancer. 2012;11:637-44.

22. Huizenga CR, Lowstuter $\mathrm{K}$, Banks $\mathrm{KC}$, et al. Evolving perspectives on genetic discrimination in health insurance among health care providers. Familial Cancer. 2010;9:253-60

23. Cataldo JK, Slaughter $\mathrm{R}$, Jahan TM, et al. Measuring stigma in people with lung cancer: psychometric testing of the Cataldo lung cancer stigma scale. Oncol Nurs Forum. 2011:38:E46-54.

24. Kissane DW, Patel SG, Baser RE, et al. Preliminary evaluation of the reliability and validity of the shame and stigma scale in head and neck cancer. Head Neck. 2013;35:172-83.

25. Bao Y, Pan S. Differences-seeking Approach in Qualitative Method and Its Theoretical Foundation. Sociol Rev China. 2015;3:89-96. (in Chinese)

26. Marlow LA, Wardle J. Development of a scale to assess cancer stigma in the non-patient population. BMC Cancer. 2014;14:285.

27. Barney L, Griffiths KM, Christensen $H$, et al. The self-stigma of depression scale (SSDS): development and psychometric evaluation of a new instrument. Int J Methods Psychiatr Res. 2010;19:243-54.

28. Polit DF, Beck CT. The content validity index: are you sure you know what's being reported? Critique and recommendations. Res Nurs Health. 2006;29: 489-97.

29. Gorsuch RL. Factor analysis (2nd ed.). Hillsdale: Erlbaum; 1983.

30. MacCallum RC, Widaman KF, Zhang $S$, et al. Sample size in factor analysis. Psychol Methods. 1999;4:84-99.

31. Yang X, Li S, Feldman MW. Development and validation of a gender ideology scale for family planning services in rural China. PLoS One. 2013;8: e59919.

32. Zhao Q, Yang L, Zuo Q, et al. Instrument development and validation of the stroke pre-hospital delay behavior intention scale in a Chinese urban population. Health Qual Life Outcomes. 2014:12:170.

33. Clark LA, Watson D. Constructing validity: basic issues in objective scale development. Psychol Assess. 1995:7:309-19.

34. Hendriks JM, Crijns HJ, Tieleman RG, et al. The atrial fibrillation knowledge scale: development, validation and results. Int J Cardiol. 2013:168:1422-8.

35. Landis JR, Koch GG. The measurement of observer agreement for categorical data. Biometrics. 1977:33:159-74.

36. Cataldo JK, Brodsky JL. Lung cancer stigma, anxiety, depression and symptom severity. Oncology. 2013;85:33-40.

37. Tang Y, Luo W. Investigation on family status of women in poor rural areas-With Tongwei county in Dingxi of Gansu as an example. J Univ Sci Technol Beijing (Soc Sci Ed). 2014;30:46-55. (in Chinese)

38. Zhang C, Lei $X$, Strauss J, et al. Health insurance and health care among the mid-aged and older Chinese: evidence from the national baseline survey of CHARLS. Health Econ. 2017;26:431-49.

39. Bouskill K, Kramer M. The impact of cancer and quality of life among longterm survivors of breast cancer in Austria. Support Care Cancer. 2016;24: 4705-12.

Ready to submit your research? Choose BMC and benefit from:

- fast, convenient online submission

- thorough peer review by experienced researchers in your field

- rapid publication on acceptance

- support for research data, including large and complex data types

- gold Open Access which fosters wider collaboration and increased citations

- maximum visibility for your research: over $100 \mathrm{M}$ website views per year

At BMC, research is always in progress.

Learn more biomedcentral.com/submissions 